\title{
NUMERICAL SIMULATION OF RUPTURE AND PROTRUSION OF VERTICALLY TIGHTENED PC BARS IN PC GIRDERS WITH ASPHALT PAVE- MENT USING APPLIED ELEMENT METHOD
}

\author{
Addisu Desalegne BONGER ${ }^{1}$, Akira HOSODA ${ }^{2}$, Hamed SALEM $^{3}$ \\ and Takahisa FUKAYA ${ }^{4}$ \\ ${ }^{1}$ Associate member of JSCE, PhD Student, Dept. of Urban Innovation, Yokohama National University \\ (79-5 Tokiwadai, Hodogaya-ku, Yokohama 240-8501, Japan) \\ E-mail: addisu-bonger-vd@ynu.jp (Corresponding Author) \\ ${ }^{2}$ Member of JSCE, Professor, Dept. of Urban Innovation, Yokohama National University \\ (79-5 Tokiwadai, Hodogaya-ku, Yokohama 240-8501, Japan) \\ E-mail: hosoda-akira-jh@ynu.ac.jp \\ ${ }^{3}$ Professor, Structural Engineering Department, Cairo University (Jamaa Street, Giza 12316, Egypt) \\ E-mail: hhadhoud@eng.cu.edu.eg \\ ${ }^{4}$ Maintenance Technology Division, Metropolitan Expressway Co., Ltd. \\ (1-4-1 Kasumigaseki Chiyoda-ku, Tokyo 100-8930, Japan) \\ E-mail: t.fukaya812@shutoko.jp
}

\begin{abstract}
Corrosion due to insufficient grout filling can result in a sudden fracture of PC steel tendons. When a vertically tightened PC tendon in PC girders is ruptured, all the accumulated strain energy is suddenly released. The ruptured PC bar will severely damage cover concrete and asphalt pavement, and PC bars may protrude out of the structure, which may cause severe accidents. In the current study, the effects of $15 \mathrm{~mm}$ cover concrete and two-layered asphalt pavement system on preventing protrusion of PC bars were investigated. Numerical simulation of rupture and protrusion of PC bars were studied using the Applied Element Method. The numerical simulations were verified based on the experimental results. In the process of verification, many influential parameters, such as the effects of contact stiffness between elements, fracture energy of concrete, mesh sensitivity, time interval sensitivity, material properties, and strain rate effect, were investigated. This study found that AEM numerical simulation with appropriate modeling showed good agreement with the experimental results, which exhibited the effectiveness of the asphalt pavement system with appropriate material and thickness preventing protrusion of the PC bar tendon.
\end{abstract}

Key Words : AEM, PC bar rupture, PC bar protrusion, asphalt pavement, countermeasure

\section{INTRODUCTION}

Vertical PC tendons have been used primarily to enhance the shear capacity in a bridge superstructure ${ }^{1)-3}$. $\mathrm{PC}$ bridges in which cracking is mitigated by prestress, are generally considered to be highly durable ${ }^{4}$. However, several problems associated with bonded post-tensioned construction occur as a result of inadequate grout injection or poor-quality grout. This has been documented in numerous research studies and field investigations ${ }^{5)-14)}$.

Corrosion-related deterioration of poorly grouted and inadequately protected tendons has also been well documented ${ }^{15), 16)}$. Many post-tensioned concrete bridges have been reported to have ruptured tendons due to corrosion ${ }^{17-20)}$. When a vertically tightened $\mathrm{PC}$ bar tendon is ruptured, all the strain energy in the PC bar is suddenly released, which can damage cover concrete and asphalt pavement ${ }^{21), 22)}$. The sudden rupture of prestressing tendon sometimes results in the protrusion of a torn portion from the bridge, causing a serious public safety hazard from projecting bars and from falling concrete because such fractures can occur with no advance warning 21),23)-25).

According to the authors' investigation in 2018 ${ }^{26)}$, there were 19,657 vertical PC bars in Metropolitan Expressway (MEX) in Japan, $54.4 \%$ of which were used in the webs of main girders. About $93 \%$ of the vertical PC bars had a length shorter than $3 \mathrm{~m}$. Actual rupture of a vertical PC bar was investigated by the 


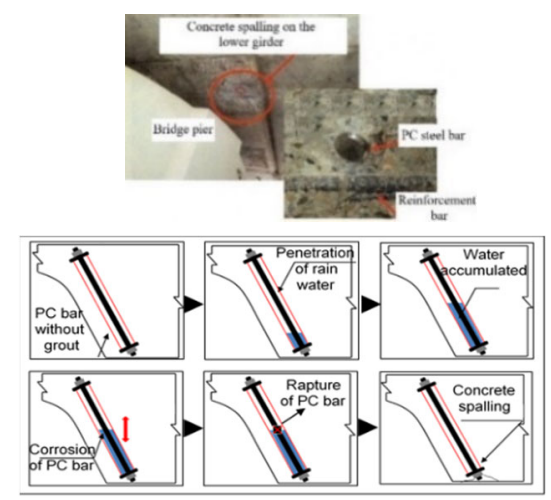

Fig.1 Rupture of vertical PC bar in MEX 26), 27)

authors as shown in Fig.1. PC bar was ordinary PC steel bar JIS B type (diameter $32 \mathrm{~mm}$ and length $2,620 \mathrm{~mm}$ ). After extracting the PC bar from the sheath, it was confirmed that the bar was ruptured at $1,345 \mathrm{~mm}$ from the bottom side and detailed invest gation was carried out to study the rupture mechanism. It was concluded that the rupture of the bar was brittle and initiated from corrosion pits, which must have been caused by cyclic drying and wetting due to the ingress of rainy water ${ }^{26), 27)}$.

Protective measures against eruption of $\mathrm{PC}$ bar tendon are necessary to avoid damage to third party ${ }^{19)}$. Steel plate and aramid FRP sheet were used on the surface of concrete as a countermeasure against protrusion of $\mathrm{PC}$ bar $^{28)}$. However, using steel plate and aramid fiber as a PC bar protrusion prevention takes a longer construction time, which is not recommended for MEX as the traffic volume is as large as 1,020,000 vehicles/day. In this research, a PC bar protrusion prevention without using steel plate and aramid fiber is investigated. Numerical simulation of rupture and protrusion of PC steel bars are conducted using the Applied Element Method (AEM) due to its advantages of simulating structural progressive collapse ${ }^{29)-33)}$.

The objective of the present study is to numerically investigate the effects of cover concrete and asphalt pavement system on preventing the protrusion of PC bars and concrete spalling. Experimental results are used for validation of numerical investigations. The numerical simulation is required to investigate the protrusion behavior of $\mathrm{PC}$ bar and the failure mechanism of asphalt pavement countermeasure. The numerical simulation tool developed in this study will be utilized for evaluating the effectiveness of countermeasures considering several practical scenarios that cannot be fully covered by experimental investigations. The effects of time-dependent deteriorations and temperatures will also be numerically investigated in the near future.

In this study, two cases are investigated. The first case has $15 \mathrm{~mm}$ cover concrete (assuming bottom of a bridge girder), while the second one has $80 \mathrm{~mm}$ thick asphalt pavement with no cover concrete (assuming top of a bridge girder). The numerical simulations are verified based on the experimental results. In the process of verification, many influential parameters, such as the effects of contact stiffness between separated elements, fracture energy of concrete, mesh sensitivity, time interval sensitivity, material properties, and strain rate effect are investigated.

\section{EXPERIMENTAL PROGRAM}

\section{(1) Details of specimens}

The details of the first specimen with $15 \mathrm{~mm}$ cover concrete simulating the bottom of a bridge girder are shown in Fig.226). PC bar rupture length was $4.5 \mathrm{~m}$. In MEX, there are very few vertical PC bars longer than $4.5 \mathrm{~m}$. The diameter of the PC bar tendon was $\phi 32 \mathrm{~mm}$ and that for the sheath was $\phi 45 \mathrm{~mm}$. The sheath was not grouted. Cover concrete was $15 \mathrm{~mm}$.

The details of the second specimen with $80 \mathrm{~mm}$ thick asphalt pavement simulating the top of a bridge girder are shown in Fig.3. PC bar rupture length was $4.5 \mathrm{~m}$. The diameter of the PC bar tendon was $\phi 32$ $\mathrm{mm}$ and that for the sheath was $\phi 45 \mathrm{~mm}$. The sheath was not grouted. Cover thickness was $0 \mathrm{~mm}$ simulating the worst situation in reality. Two-layered asphalt pavement was provided in this specimen. The asphalt pavement system had a total thickness of $80 \mathrm{~mm}$ with $2 \mathrm{~m} \times 2 \mathrm{~m}$ area. The base layer in the two layers had a thickness of $50 \mathrm{~mm}$, and the cover layer had a thickness of $30 \mathrm{~mm}$. Figure 4 shows the fabrication of this specimen. The base layer and the cover layer were placed over a $2 \mathrm{~m} \times 2 \mathrm{~m} \mathrm{RC}$ concrete (the first part) and compacted layer by layer. Then, it was transported to the experiment site and connected to the second part of the specimen. The two RC concrete parts were connected using connecting PC bars $(\phi 32$ $\mathrm{mm})$. A coupler was used to connect the main PC bar tendons. The coupler did not affect the experimental results.

\section{(2) Materials}

The concrete had a compressive strength of 40 $\mathrm{MPa}, 80 \mathrm{~mm}$ slump, and $4.5 \%$ air volume. The PC bar tendon was standard steel bar: SBPR930/1180 (class B2 in JIS). The applied prestress force, after the prestress loss due to relaxation, creep and shrinkage, was $591 \mathrm{kN}\left(0.6 \mathrm{P}_{\mathrm{u}}\right)$. Strain energy of the PC bar was $4,408 \mathrm{~J}$. The two asphalt pavement layers (cover layer and base layer) had different material properties. Bending tests for asphalt materials were conducted in this study. Non-shrinking mortar was used in the anchor zone, whose compressive strength was $60 \mathrm{MPa}$. 

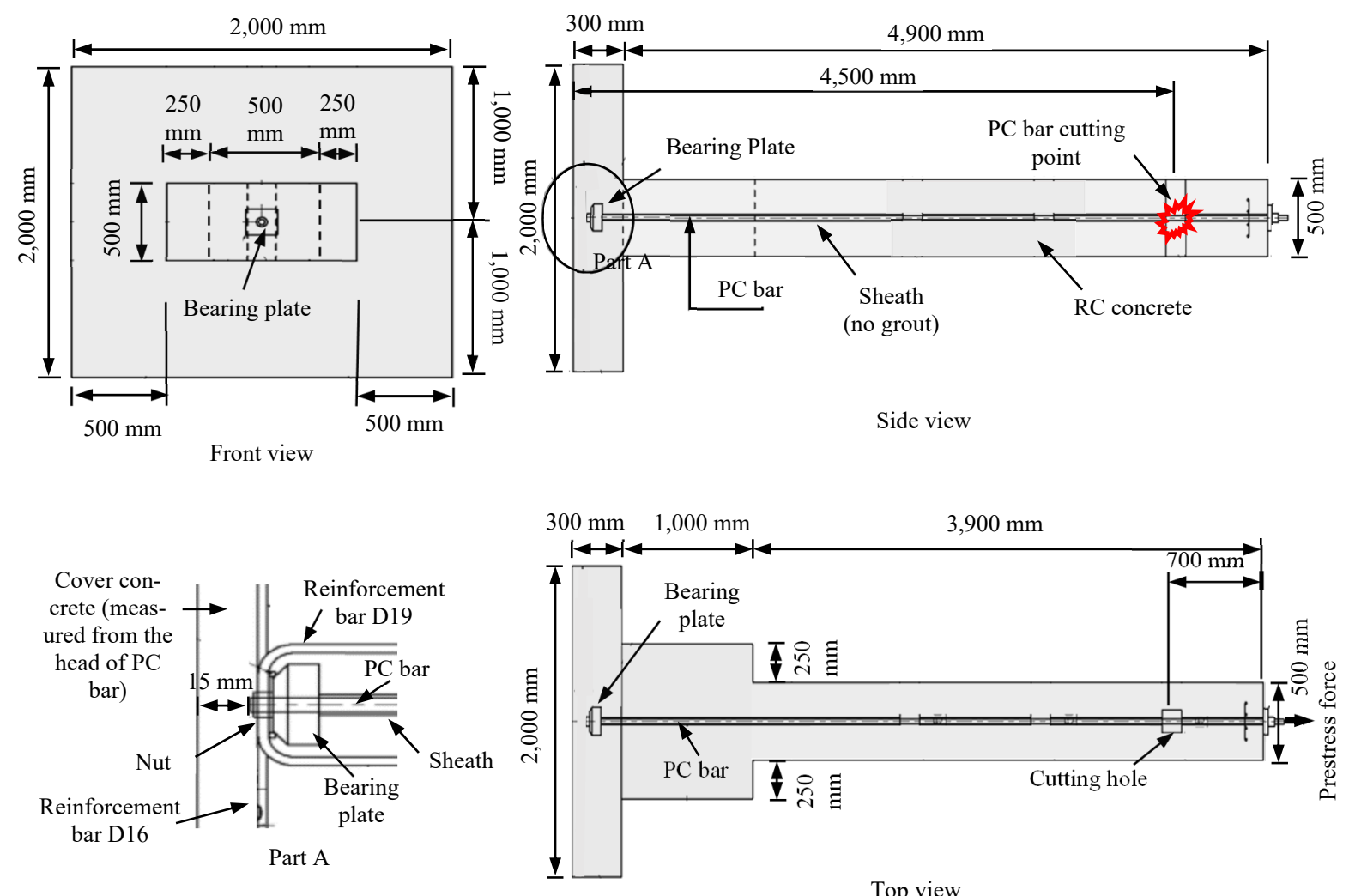

Fig.2 Specimen details with $15 \mathrm{~mm}$ cover concrete ${ }^{26)}$.
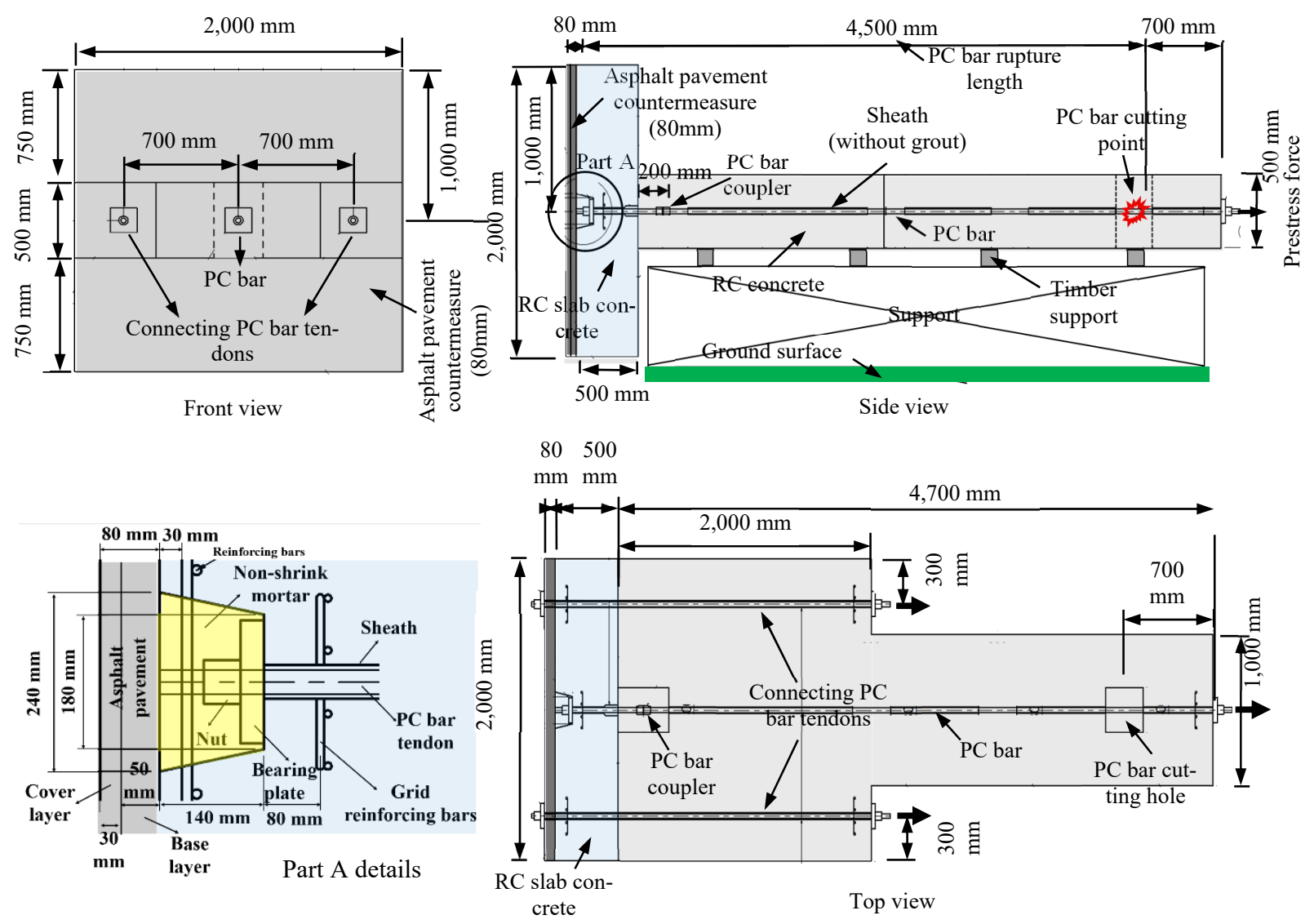

Fig.3 Specimen details with $80 \mathrm{~mm}$ thick asphalt pavement. 


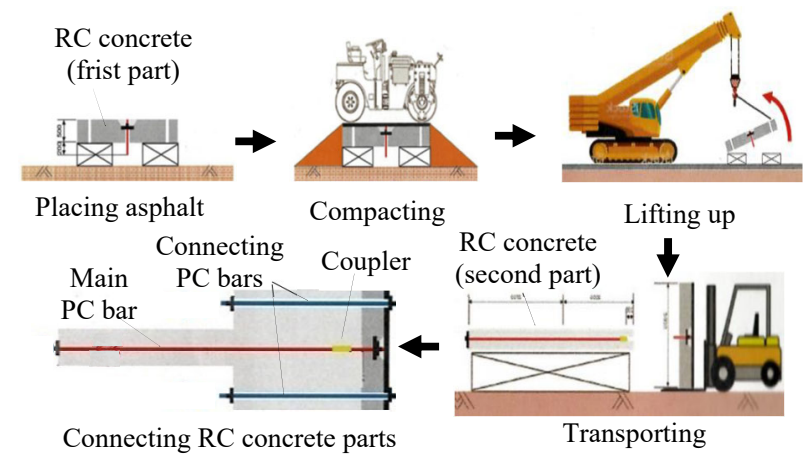

Fig.4 Fabrication of the specimen with $80 \mathrm{~mm}$ thick asphalt pavement.

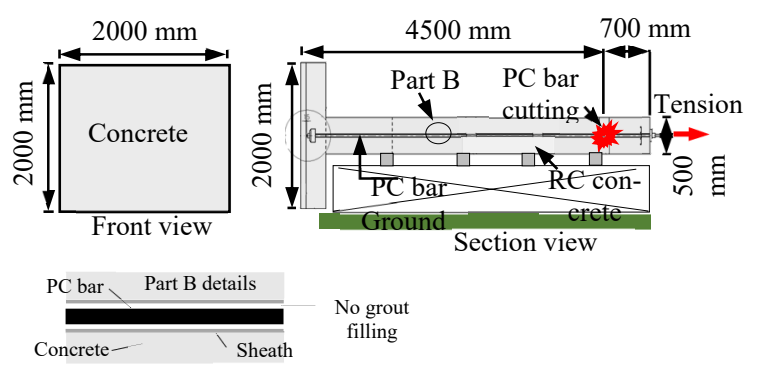

Fig.5 Experimental setup for the specimen with $15 \mathrm{~mm}$ cover concrete.

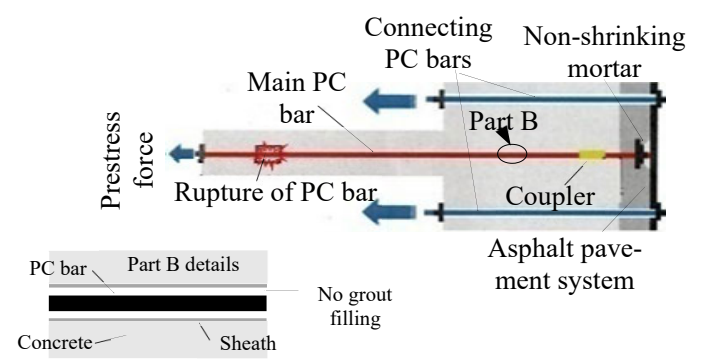

Fig.6 Experimental procedure for the specimen with $80 \mathrm{~mm}$ thick asphalt pavement.

\section{(3) Testing procedure}

Figure 5 shows the experimental setup for the first specimen. The PC bar was inserted into the sheath. The PC bar had no contact with the sheath during prestressing. The sheath was not grouted. Tension force was applied to the PC bar. The PC bar was cut using a grinder at $4.5 \mathrm{~m}$ from the PC bar head. Then, the protrusion of the PC bar and concrete spalling were investigated.

Figure 6 shows the experimental procedure for the second specimen. The main PC bar and the connecting PC bars were inserted into the sheath. The main PC bar and the connecting PC bars had no contact with the sheath during prestressing. The sheath was not grouted. Tension force was applied to the main PC bar and the connecting PC bars. Non-shrinking mortar was placed in the anchor zone. The main PC bar was cut using a grinder at $4.5 \mathrm{~m}$ from the $\mathrm{PC}$ bar head. Then, the effectiveness of the asphalt pavement system was investigated.

\section{APPLIED ELEMENT METHOD (AEM)}

Applied Element Method (AEM) is based on dividing the structural members into virtual elements connected through springs. Each spring entirely represents the stresses, strains, deformations, and failure of a certain portion of the structure. AEM allows the performance of static and dynamic analysis ${ }^{29)-33)}$. In this study, a nonlinear structural analysis software 'Extreme Loading for Structure (ELS)' ${ }^{34}$ ) based on AEM was used.

The solution for dynamic problems adopts the step-by-step integration (Newmark beta) method. For nonlinear dynamic phenomenon, the numerical solution can be obtained by a sufficiently small-time interval. The time interval required for stable dynamic analysis is a function of element mass and contact

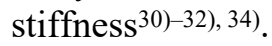

In ELS, elements may separate and contact, recontact again, or contact other elements. When two elements with different material properties collide, the spring properties are governed by the material with softer properties. When contact occurs between elements, three contact springs are added at each contact point; one normal spring and two shear springs. The stiffness values for the normal contact spring and the shear contact spring are shown in equation (1) and (2). Those springs are linear springs that transfer energy between the elements as shown in Fig. ${ }^{\text {74). }}$.

The contact normal spring stiffness is calculated as:

$$
K_{n}=E N F D
$$

where $K_{n}(\mathrm{~N} / \mathrm{mm})$ is contact normal spring stiffness, $E\left(\mathrm{~N} / \mathrm{mm}^{2}\right)$ is Young's Modulus of softer material of the two collided elements, $N F$ is normal contact stiffness factor, and $D(\mathrm{~mm})$ is the distance between the centers of contacting elements.

The contact shear spring stiffness is calculated as:

$$
K_{S}=G S F D
$$

where $K_{s}(\mathrm{~N} / \mathrm{mm})$ is contact shear spring stiffness, $G\left(\mathrm{~N} / \mathrm{mm}^{2}\right)$ is shear Modulus of softer material of the two collided elements, $S F$ is shear contact stiffness factor, and $D(\mathrm{~mm})$ is the distance between the centers of contacting elements. When shear force is larger than (friction coefficient $\times$ Normal force), the shear stiffness is multiplied by the minimum shear stiffness factor (0.001).

Contact Spring Unloading Stiffness Factor $(n)$ express the effect of energy dissipation during contact. Referring to Fig.7(c), the ratio between unloading and loading stiffness is defined as $n$. For example, a value of unity for $n$ means no energy dissipation during collision, while a value of 2 means half the kinetic 


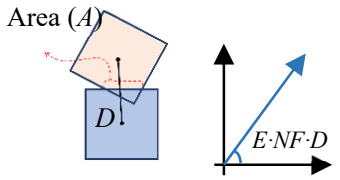

(a) Stiffness value of normal spring when contact occurs

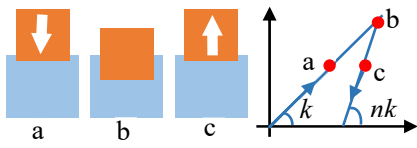

(c) Contact spring unloading stiffness factor

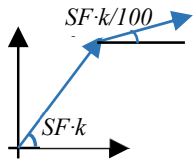

(b) Stiffness value of shear spring when contact occurs

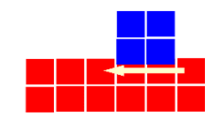

(d) Friction between two contacting elements
Fig.7 Element contacts in ELS.

energy is lost due to collision.

In ELS, friction coefficient $(\mu)$ is available for all material models. It is effective when the contact springs between elements are generated (Fig.7(d)) $)^{34)}$.

Many research papers have been published on the successful use of AEM to simulate structural progressive collapse ${ }^{35)-42 \text { ). }}$

\section{SENSITIVITY ANALYSIS FOR ELE- MENT CONTACT AND TIME INTER- VAL}

\section{(1) Element contact sensitivity analysis}

The contact between the PC bar and the sheath has an effect on PC bar protrusion. In the experiment of the first specimen shown in Fig.2, after the rupture of the PC bar, a camera was inserted into the sheath to detect the contact between the PC bar and the sheath. Eight contact locations were detected as shown in Fig.8(a). At locations 1 to 4, the PC bar contacted the sheath with no severe damage. While the PC bar was protruding in the sheath, the gravity pulled the PC bar down and impacted the sheath with more damage at locations 5, 6, 7, and 8. At location 5, the PC bar contacted the sheath on the top surface of the sheath; however, at locations 6,7 , and 8 , the contact was on the bottom surface of the sheath (Fig.8(b)). Similarly, element contact between the PC bar and the sheath was observed in the numerical simulation ${ }^{26)}$ as shown in Fig. 8(c). After the rupture of the PC bar, the distribution of normal force in the PC bar was not constant. This could be explained by a dynamic wave transmission along the bar due to sudden loss of its axial force. This caused the PC bar to be energetic and unstable while protruding in the sheath. When the PC bar moved inside the sheath, gravity pulled the PC bar down and made contact with the sheath.

The effects of element contacts were investigated using a simplified model26). This simplified model (Fig.9) was prepared based on the details shown in Fig.2, where the concrete and the reinforcement bars

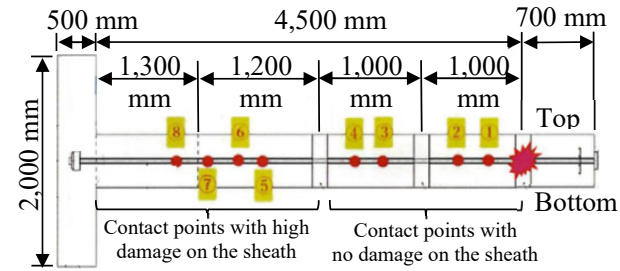

(a) Location of contact between the PC bar and the sheath in the experiment

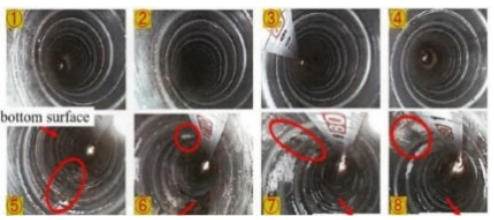

(b) Contact between the PC bar and the sheath in the experiment

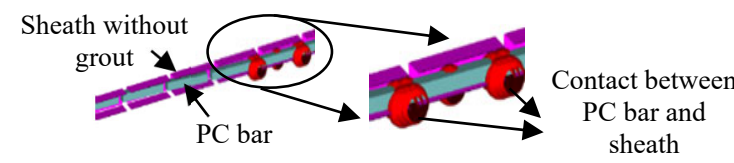

(c) Contact between the PC bar and the sheath in AEM simulation

Fig.8 Contact between the PC bar and the sheath.

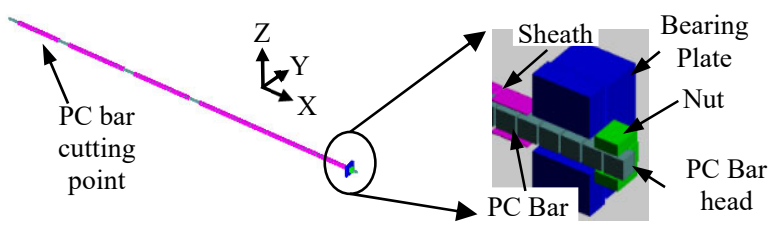

Fig.9 Simplified numerical model to study the effect of element contact $^{26)}$.

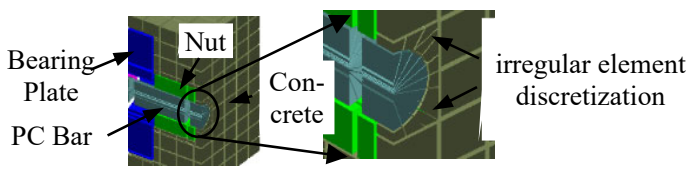

Fig.10 Irregular element discretization in ELS.

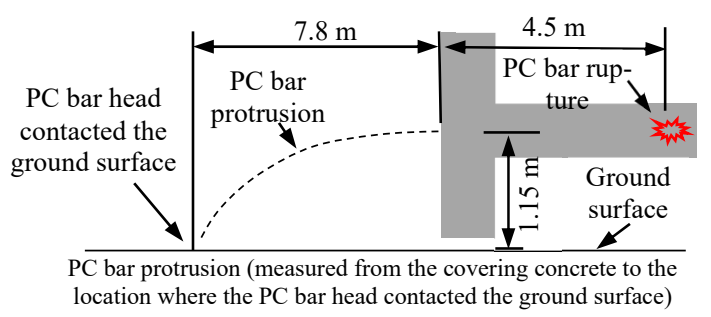

Fig.11 Illustration of PC bar protrusion in the experiment.

were removed to reduce analysis time. In this case, the bearing plate and the sheath were completely restrained. Rupture length was $4.5 \mathrm{~m}$ from the PC bar head. The "bearing material" in ELS, which can transfer only compression, was used for the interface between the PC bar and the sheath, and for the interface between the PC bar and the bearing plate. Table 1 shows the geometry and materials of the simplified model. 
Table 1 Geometry and materials for simplified model.

\begin{tabular}{|ccccc|}
\hline & \multicolumn{2}{c}{ Geometry } & & \\
\cline { 2 - 4 } Objects & $\begin{array}{c}\text { Cross Section in Y and Z axis } \\
(\mathrm{mm})\end{array}$ & $\begin{array}{c}\text { Length along X } \\
\text { axis }(\mathrm{mm})\end{array}$ & Element size $(\mathrm{mm})$ & Material \\
\hline PC bar & $28.36 \times 28.36$ & 5,336 & $28.36 \times 28.36 \times 28.36$ & High strength \\
Nut & $62 \times 62$ & 34 & $34 \times 62 \times 62$ & steel \\
Bearing & $160 \times 160(40 \times 40$ hole $)$ & 84 & $84 \times 160 \times 160$ & Normal steel \\
Plate & $40 \times 40$ & 5,060 & $126 \times 40 \times 40$ & \\
Sheath & & & & \\
\hline
\end{tabular}

In this study, a rectangular-shaped PC bar, sheath, and nut were used to avoid irregular element discretization. When the concrete intersected with roundshaped PC bar and nut, irregular-shaped elements formed as shown in Fig.10. This had effect on shear crack formation in the concrete when the PC bar impacted with the concrete. However, when a rectangular PC bar and sheath were used, the contacting area between the PC bar and the sheath was larger than the contacting area between the round PC bar and sheath. The contacting area between the PC bar and the sheath had an effect on PC bar protrusion. Therefore, appropriate contact parameters should be used to accurately obtain the PC bar protrusion as shown in Fig.11.

From parametric study using the simplified model (Fig.9), it was found that the element contact parameters (coefficient of friction $(\mu)$, normal contact stiffness factor $(N F)$, shear contact stiffness factor $(S F)$, and contact spring unloading stiffness factor (n)) had noticeable effects on the PC bar protru$\operatorname{sion}^{26)}$. When one of the element contact parameter was evaluated, the other element contact parameters were fixed as default values. For example, when $N F$ value of the PC bar was evaluated at $1.0 \mathrm{E}-0.8$, the other contact parameters $(S F, \mu$ and $n)$ of the PC bar and $N F, S F, \mu$, and $n$ of sheath, bearing plate and ground surface were set to the default values. In ELS, The default values of the element contact parameters $(N F, S F, \mu$, and $n)$ are 1.0E-0.4, 1.0E-0.5, 0.8, and 2, respectively. The following charts show the effects of element contact on protrusion of the PC bar. In this study, the PC bar protrusion length was measured from the surface of covering concrete (Fig.11).

The results of this parametric study indicated that the $N F$ values of the PC bar smaller than around 1.0 $\times 10^{-6}$ had a significant effect on the PC bar protrusion. The PC bar protrusion was around $8,000 \mathrm{~mm}$ when the $N F$ value was less than $1.0 \times 10^{-8}$. The PC bar protrusioin decreased to $870 \mathrm{~mm}$ when the $N F$ value was greater than $1.0 \times 10^{-6}$ as shown in Fig.12(a). Setting a very high contact stiffness value of the PC bar causes a large shock force to transfer between the PC bar and the sheath, which results in a very small PC bar protrusion. Setting a low contact

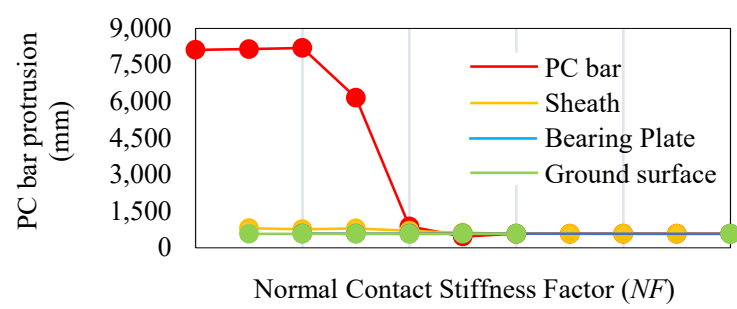

(a) Effect of Normal Contact Stiffness Factor $(N F)$

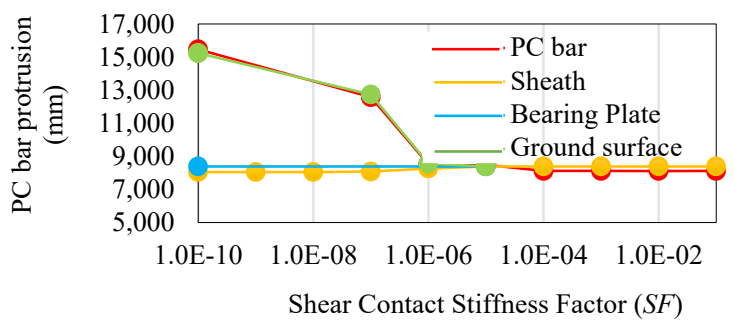

(b) Effect of Shear Contact Stiffness Factor $(S F)$

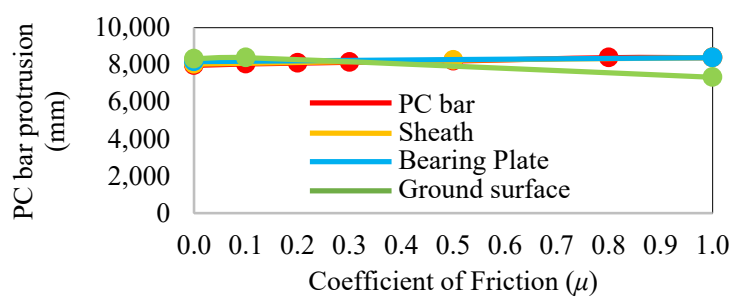

(c) Effect of coefficient of friction $(\mu)$

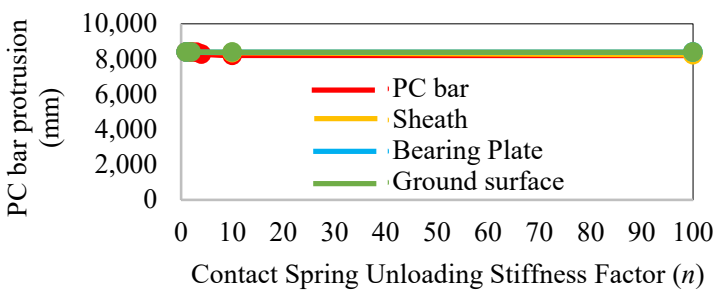

(d) Effect of contact spring unloading stiffness factor $(n)$

Fig.12 The effects of element contacts on PC bar protrusion.

stiffness value causes underestimation of transmitted forces when elements collide, which results in a very large $\mathrm{PC}$ bar protrusion and penetration of $\mathrm{PC}$ bar into the sheath. From this parametric study, $N F$ value of $0.5 \times 10^{-8}$ for the PC bar gave a result close to the experiment as shown in Fig.11. However, $N F$ values of the sheath, the bearing plate, and the bearing interface material had little effect on the PC bar protrusion. 
After setting the $N F$ value of the PC bar as $0.5 \times$ $10^{-8}$, further investigation was carried out for $S F, \mu$, and $n$. The $S F$ value of the PC bar and the ground surface material (bearing material) had a significant effect on PC bar sliding over the ground surface. The $S F$ value of the PC bar and of the ground surface material smaller than $1.0 \times 10^{-7}$ resulted in larger sliding of the PC bar over the ground surface between 13,000 $\mathrm{mm}$ and 15,000 $\mathrm{mm}$ as shown in Fig.12(b). On the other hand, $\mu$ and $n$ had little effect on the PC bar protrusion.

From the element contact analysis, it can be concluded that the $N F$ of the PC bar affects the PC bar movement inside the sheath and over the ground surface and the $S F$ of the ground surface material affects the PC bar sliding over the ground surface. Therefore, appropriate values should be set for contact spring stiffness.

\section{(2) Sensitivity analysis of time interval}

The impact force of the PC bar on cover concrete is a transient force applied in a very short time. Therefore, a sensitivity study was carried out to obtain the largest possible time increment that can be used without affecting the results. Small time interval is necessary for accurate simulation, but it will significantly increase the simulation time.

In the analysis, three stages of loading were provided. The first one was static loading to account for prestressing stage, while the second and the third ones were dynamic to simulate the rupture of the PC bar and its impact on cover concrete. In the second stage, the rupture of the $\mathrm{PC}$ bar was simulated by suddenly removing one element of the $\mathrm{PC}$ bar at the cut point. The first dynamic stage had a duration of 0.7 second with a time interval of $5.0 \times 10^{-6}$ seconds and the second dynamic stage had a duration of $0.4 \mathrm{sec}-$ ond with a time interval of $1.0 \times 10^{-3}$ seconds were found appropriate by sensitivity analysis. During the first dynamic stage, the PC bar was energetic, and the cover concrete and the asphalt pavement were under a high loading rate and it was necessary to use smaller time interval for accurate simulation. On the other hand, during the second dynamic stage, most of the energy of the PC bar was dissipated, and the crushing of concrete and asphalt pavement was almost finished. To save on simulation time, a larger time inter- val $\left(1.0 \times 10^{-3}\right.$ second $)$ was used for the second dynamic stage without affecting the result.

\section{VERIFICATION OF AEM SIMULA- TION FOR THE SPECIMEN WITH- OUT ASPHALT PAVEMENT}

AEM numerical simulation was made for the first specimen shown in Fig.2.

Geometry and materials of the PC bar, the bearing plate, the nut, and the sheath are shown in Table 1. The interface material between the sheath and the PC bar and that between the bearing plate and the PC bar were modeled using "bearing material" (a material that can transfer only compression). On the other hand, the interface material between concrete and other metal materials (the PC bar, the nut, the bearing plate, and the sheath) was modeled as normal concrete (40 MPa compressive strength).

In this research, ELS version 6 was used as a nonlinear structural analysis tool. In this version, for modelling concrete under compression, the model of Maekawa, including unloading and reloading, is adopted ${ }^{43)}$. However, for modeling of concrete under tension, fracture energy $\left(G_{f}\right)$ was not considered. According to this model, the concrete tensile stress suddenly drops to zero after reaching the tensile strength
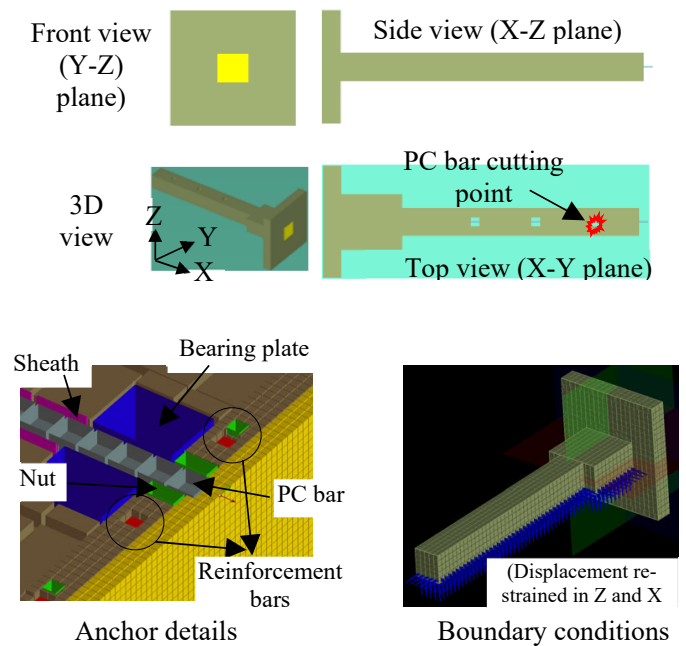

Fig.13 AEM numerical simulation ${ }^{26)}$.
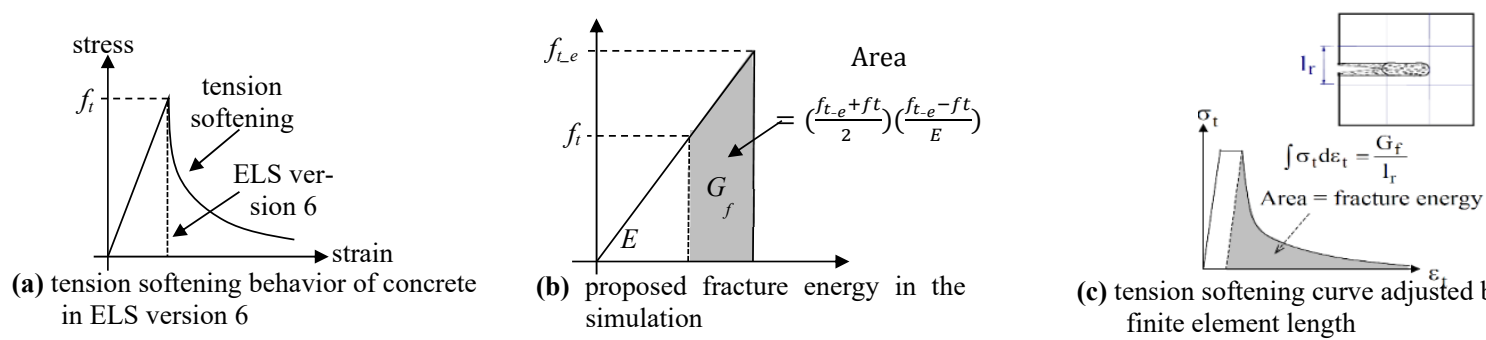

(c) tension softening curve adjusted based on finite element length

Fig.14 Consideration of fracture energy of concrete in ELS Version-6. 


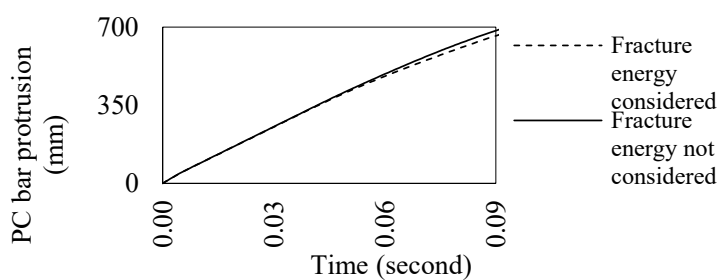

Fig. 15 Effect of proposed fracture energy of concrete on PC bar protrusion (PC bar ruptured at $1 \mathrm{~m}$ ).

as shown in Fig.14(a). To overcome this drawback and to consider the contribution of fracture energy of concrete in tension, the tensile strength $\left(f_{t}\right)$ was increased to an equivalent tensile strength $\left(f_{t_{-}}\right)$to consider fracture energy in the numerical simulation as shown in Fig.14(b). The equivalent tensile strength $\left(f_{t_{-}}\right)$can be calculated from the fracture energy of concrete using equation (3). Fracture energy of the normal concrete can be obtained from the maximum aggregate size using equation (4) ${ }^{44)}$. Figure 14(c) shows the tension softening curve adjusted based on finite element length ${ }^{45}$. Based on this method, fracture energy dependent on mesh size was considered in this research. Consideration of fracture energy using this method improved energy absorption of concrete (Fig. 15).

$$
G_{f}=\left(\frac{f_{t_{-} e}+f_{t}}{2}\right)\left(\frac{f_{t_{-} e}-f_{t}}{E}\right) \cdot l
$$

Where $G_{f}(\mathrm{~N} / \mathrm{mm})$ is fractur energy, $E\left(\mathrm{~N} / \mathrm{mm}^{2}\right)$ is Young's Modulus of concrete, $f_{t_{-} e}\left(\mathrm{~N} / \mathrm{mm}^{2}\right)$ is equivalent tensile strength, and $l(\mathrm{~mm})$ is element size.

$$
G_{f}=10\left(d_{\max }\right)^{1 / 3}\left(f_{c k}^{\prime}\right)^{\frac{1}{3}}
$$

Where $G_{f}(\mathrm{~N} / \mathrm{m})$ is fracture energy, $d_{\max }(\mathrm{mm})$ is maximum aggregate size, and $f_{c k}^{\prime}\left(\mathrm{N} / \mathrm{mm}^{2}\right)$ is compressive strength

Figure 16 shows the protrusion of the $\mathrm{PC}$ bar and concrete spalling both in the experiment and in the numerical simulation at different times. The protrusion of the PC bar was very fast and energetic. At around 0.4 second after the rupture, the PC bar was fully outside of the sheath. The numerical simulation showed that, at 0.584 second, the PC bar made first contact with the ground surface $(7.1 \mathrm{~m}$ from the cover concrete). On the other hand, the experiment showed that the PC bar made first ground contact at around $0.6-0.7$ second ( $7.8 \mathrm{~m}$ from the cover concrete). The AEM numerical simulation showed good agreement with experimental results in terms of protrusion behavior.

The $15 \mathrm{~mm}$ cover concrete was destroyed and spalled. The cover concrete spalling had a size of around $40 \mathrm{~cm} \times 43 \mathrm{~cm}$ area (Fig.17(a)). The concrete
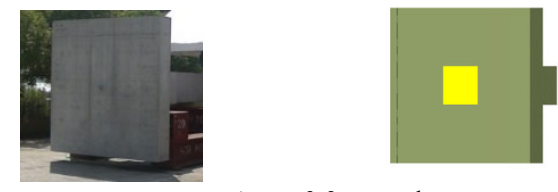

At $t=0.0$ second
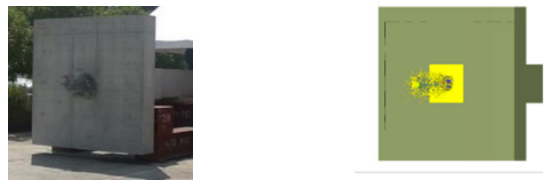

At $t=0.05$ second
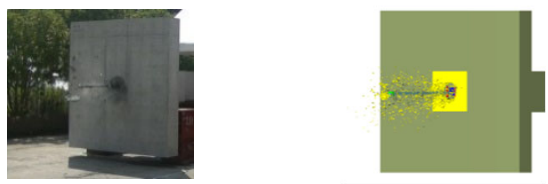

At $t=0.1$ second
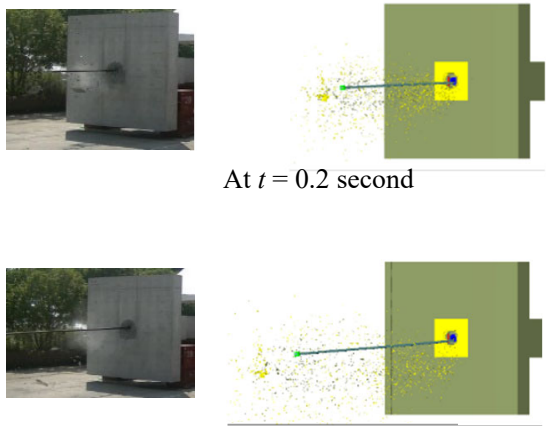

At $t=0.3$ second
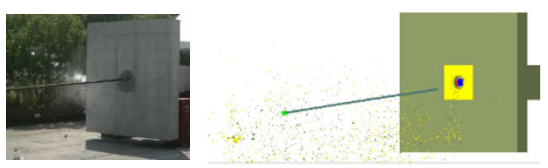

At $t=0.4$ second
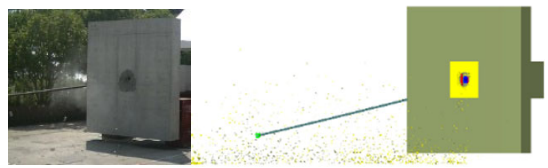

At $t=0.5$ second

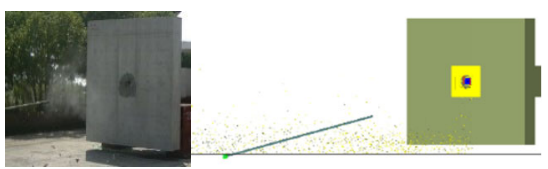

At $t=0.6$ second
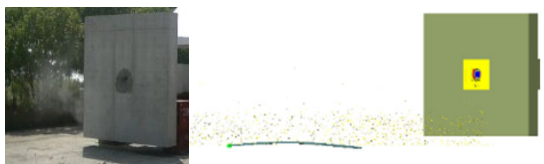

At $t=0.7$ second

Fig.16 AEM numerical simulation about protrusion of $\mathrm{PC}$ bar ${ }^{26)}$. 

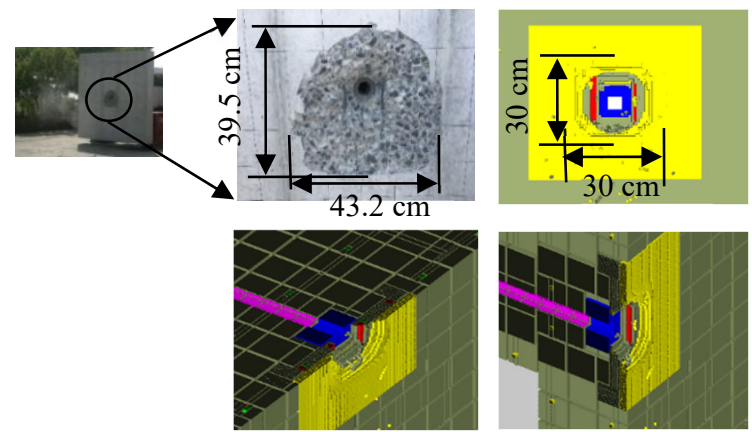

(a) Cover concrete spalling

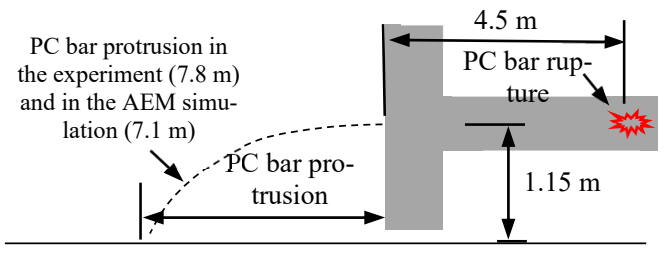

(b) illustration of position of PC bar protrusion

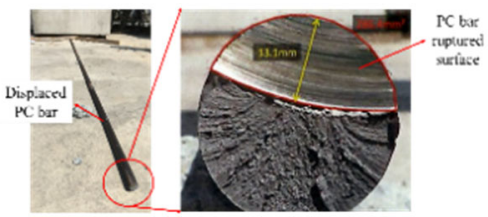

(c) PC bar ruptured surface

Fig.17 Cover concrete spalling, illustration of $\mathrm{PC}$ bar protrusion and $\mathrm{PC}$ bar ruptured surface ${ }^{26)}$.

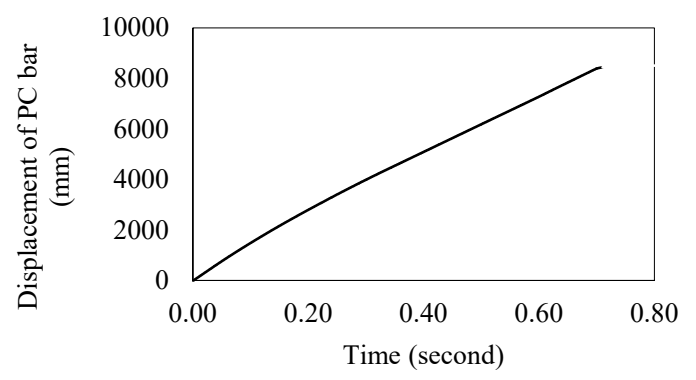

(a) Protrusion of PC bar (AEM numerical simulation)

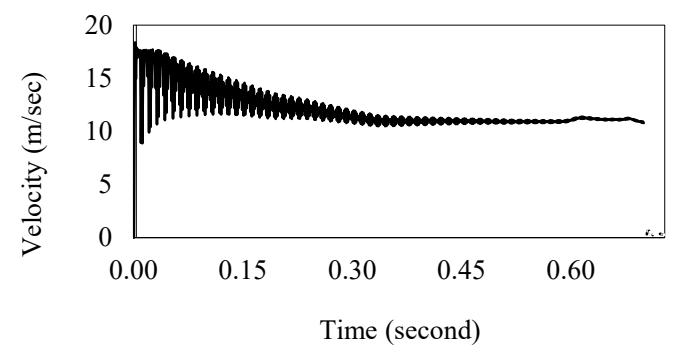

(b) Velocity of PC bar (AEM numerical simulation)

Fig.18 Protrusion of PC bar and velocity of PC bar ${ }^{26)}$.

spalling was limited to the center of the specimen. One of the reasons could be the large amount of reinforcing bars in the cover concrete, which were arranged to prevent damaging during prestressing.
Figure 18(a) shows the progress of the protrusion of the PC bar. The velocity of the PC bar was also investigated. The investigation results indicated that the velocity of the PC bar was fluctuating (not steady throughout the dynamic stage (Fig.18(b)). The main reason was that the distribution of normal force in the PC bar was not constant throughout the time. This could be explained by a dynamic wave transmission along the bar due to sudden loss of its axial force.

The strain rate was checked in the numerical simulation results for the normal spring between the PC bar and the cover concrete and between the nut and the cover concrete. The average maximum strain rate for the spring between the PC bar and the cover concrete was found to be $97.7 /$ second and that for the spring between the nut and the cover concrete was $89.7 /$ second. For plain concrete under high loading rate, the compressive strength, tensile strength, and elastic modulus should be increased with an increase in strain rate ${ }^{46)}$-48). The dynamic increase factors $(D I F)$, the ratio of the dynamic strength to quasistatic strength, of concrete under compression and tension at a high loading rate (strain rate $>30 / \mathrm{s}$ ) can be calculated using equation (5) and (6) ${ }^{49}$. In the numerical simulation, for the normal spring between the $\mathrm{PC}$ bar and the cover concrete and between the nut and the cover concrete, the quasi-static compressive and tensile strengths and Young's Modulus of concrete were multiplied by the respective $D I F$ as shown in Table 2. For example, $83.6 \mathrm{MPa}$, a product of 40MPa quasi-static strength and DIF of 2.09 , was used as compressive strength for the spring between the PC bar and the cover concrete.

$$
\begin{aligned}
& D I F_{\text {compression }}=f_{c d}^{\prime} / f_{c s}^{\prime}=c\left(\dot{\varepsilon} / \dot{\varepsilon}_{s}\right)^{\frac{1}{3}} \\
& D I F_{\text {tension }}=f_{t d} / f_{t s}=d\left(\dot{\varepsilon} / \dot{\varepsilon}_{s}\right)^{\frac{1}{3}}
\end{aligned}
$$

$$
\begin{array}{ll}
a=1 /\left(5+0.9 f_{c S}^{\prime}\right) & b=1 /\left(10+0.6 f_{c S}^{\prime}\right) \\
c=10^{(6.156 a-2)} & d=10^{(7.112 b-2.33)}
\end{array}
$$

where $f^{\prime} c d, f_{t d}$ are compressive and tensile strengths at rapid loading; $f_{c s}^{\prime}, f_{t s}$ are compressive and tensile strengths at static loading; $\dot{\varepsilon}$ is strain rate at rapid loading; and $\dot{\varepsilon_{\mathrm{s}}}$ is strain rate at static loading $(30 \times$ $10^{-6}\left[\mathrm{~s}^{-1}\right]$ for compressive loading and $3 \times 10^{-6}\left[\mathrm{~s}^{-1}\right]$ for tensile loading).

$D I F$ for Young's modulus is expressed as follows ${ }^{46)}$ :

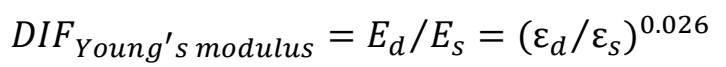

where $E_{d}$ is dynamic modulus, $E_{s}$ is static modulus, 
Table 2 The Dynamic Increase Factors.

\begin{tabular}{|ccc|}
\hline & \multicolumn{2}{c|}{ Dynamic Increase Factor $(D I F)$} \\
\cline { 2 - 3 } & Springs between & Springs between \\
Material Proper- & PC bar and cover & nut and cover \\
ties & concrete & concrete \\
\hline Young's modulus & 1.48 & 1.47 \\
Tensile strength & 2.42 & 2.35 \\
Compressive & 2.09 & 2.03 \\
strength & & \\
\hline
\end{tabular}

$\varepsilon_{\mathrm{s}}$ is static strain rate $=30 \times 10^{-6}\left[\mathrm{~s}^{-1}\right]$, and $\varepsilon_{d}$ is dynamic strain rate.

\section{VERIFICATION OF NUMERICAL SIM- ULATION FOR THE SPECIMEN WITH ASPHALT PAVEMENT}

\section{(1) Bending test of asphalt}

AEM numerical simulation was carried out for the base layer asphalt material and the cover layer asphalt material to calibrate tensile stress-tensile strain relationships for the two asphalt materials. The asphalt specimens had a dimension of $300 \mathrm{~mm} \times 100 \mathrm{~mm} \times$ $50 \mathrm{~mm}$ (Fig.19(a)). The load was applied at the midspan. The distance between the pinned supports was $200 \mathrm{~mm}$ (each pinned support was $100 \mathrm{~mm}$ from the midspan). In the numerical simulation, the asphalt pavement had an element size of $5 \mathrm{~mm} \times 5 \mathrm{~mm} \times 5$ $\mathrm{mm}$. The applied displacement was $20 \mathrm{~mm}$. In this study, the asphalt pavement materials were simulated using a bilinear model with softening range, which was the most approprtiate material in ELS. Figure 19(c) and Fig.19(d) show the tensile stress-tensile strain relationships for the cover layer and the base layer. The numerical simulation was verified with the experiment. The experiment was carried out at a temperature of $20^{\circ} \mathrm{C}$.

The relationships between load and displacement are shown in Fig.20. In the cover layer asphalt pavement, the observed maximum load in the numerical simulation was $1,059 \mathrm{~N}$ at a displacement of 6.95 $\mathrm{mm}$. The first crack on the bottom surface of the specimen at the midspan was observed at a load of $697 \mathrm{~N}$ and at a displacement of $11.40 \mathrm{~mm}$. After that, the crack gradually propagated upward until the complete collapse of the specimen. The cover layer showed a relatively lower capacity with a larger deformation.

On the other hand, in the base layer asphalt pavement, the observed maximum load was $11,138 \mathrm{~N}$ at a displacement of $2.51 \mathrm{~mm}$. And the first crack was observed at this maximum load on the bottom surface at

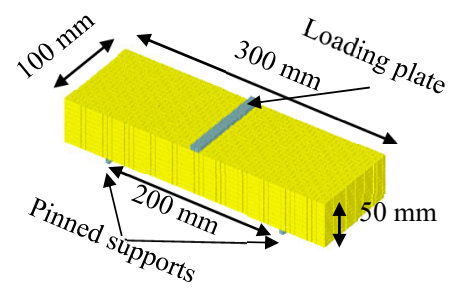

(a) AEM simulation modeling

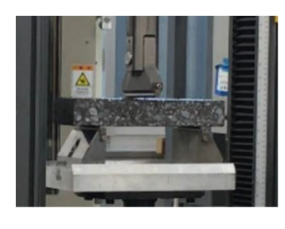

(b) Experiment

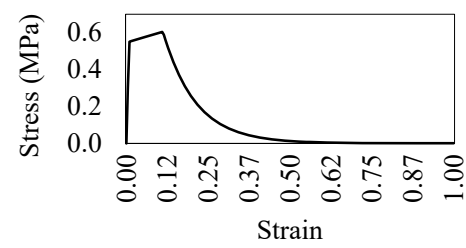

(c) Cover layer material

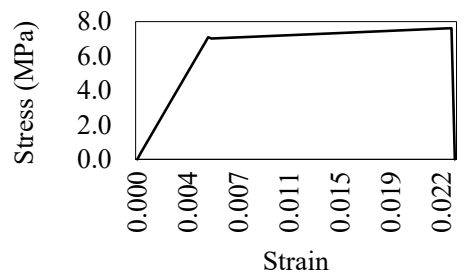

(d) Base layer material

Fig.19 Asphalt pavement bending test and material properties of cover layer and base layer.

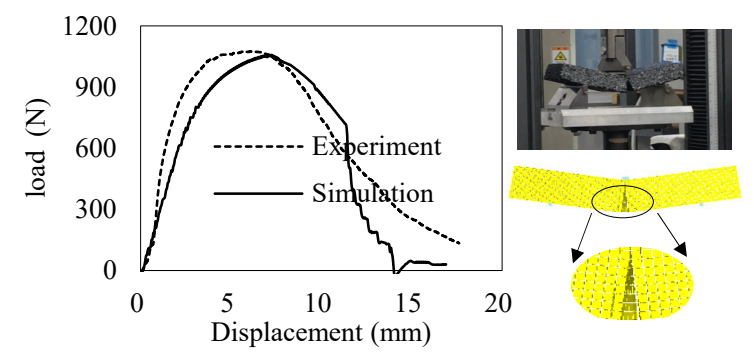

(a) Cover layer asphalt pavement

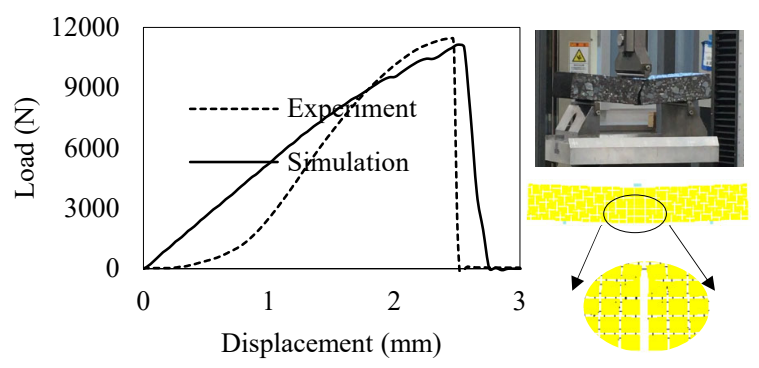

(b) Base layer asphalt pavement

Fig.20 Relationship between load and displacement for cover layer and base layer.

the midspan of the specimen. After that, the load suddenly dropped to zero without showing additional deformation. It showed brittle failure. 


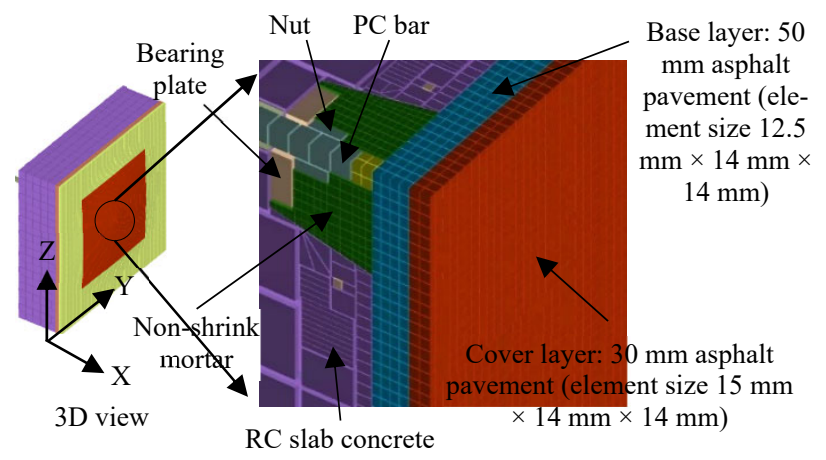

(a) AEM simulation modeling

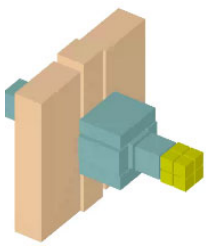

(b) Anchor

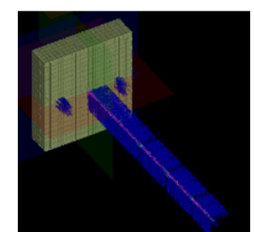

(c) Boundary conditions
Fig.21 Modeling for AEM numerical simulation considering asphalt pavement.

\section{(2) Verification of numerical simulation for the ef-} fects of asphalt pavement

AEM numerical simulation was made for the second specimen explained in Fig.3. The details of the modeling about the PC bar tendon and the sheath are shown in Fig.9. The details of loading stages were already explained in Section 4(2).

The interface material between the PC bar and the non-shrinking mortar, between the nut and the nonshrinking mortar, and between the bearing plate and the non-shrinking mortar was modeled as mortar with compressive strength of $60 \mathrm{MPa}$. The cover layer and the base layer were modeled as bilinear materials (material properties are shown in Fig.19). Similarly, the interface materials between the slab concrete and the base layer and between the cover layer and the base layer were modeled as bilinear materials.

It is difficult to set appropriate material properties for interface materials directly based on experimental results. When a bond between the base layer and the slab concrete had a very high yield strength, separation between the slab concrete and the asphalt base layer did not occur and it was difficult to obtain ductile asphalt pavement deformation. As a result, localized asphalt pavement failure and $\mathrm{PC}$ bar protrusion occurred as shown in Fig.22(a). In Section 6, PC bar protrusion was measured on the $\mathrm{PC}$ bar head before and after PC bar rupture. On the other hand, a weak interface material resulted in a total delamination between the asphalt base layer and the slab concrete in the specimen with this size, and the protrusion of PC bar could not be prevented as shown in Fig.22(b).

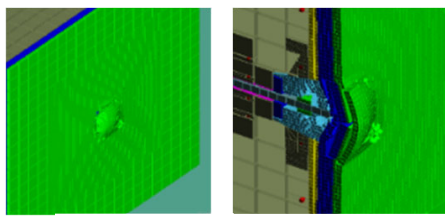

(a) strong interface bond

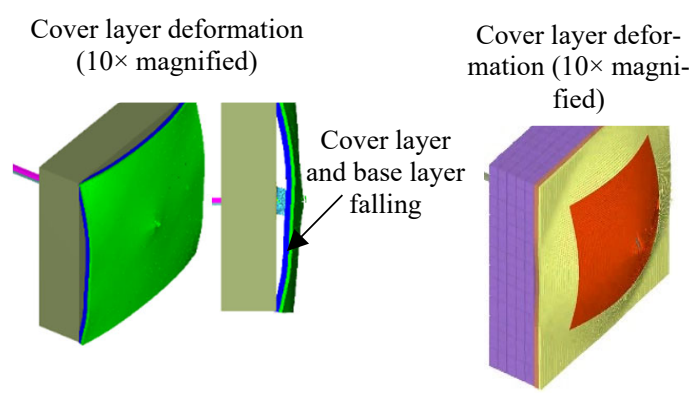

(b) weak interface bond

(c) $3.45 \mathrm{MPa}$ interface bond strength between the base layer and the slab concrete

Fig.22 The effects of bond at interface between asphalt base layer and slab concrete on the asphalt pavement deformation and on the failure mode.
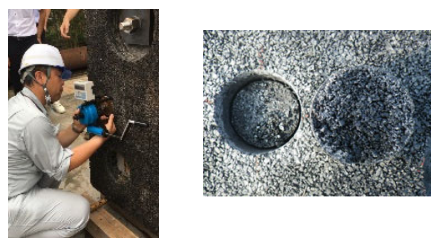

Fig.23 Asphalt pavement pull-off test.

Asphalt pavement pull-off test was carried out to measure the interface bond strength between the slab concrete and the base layer asphalt pavement as shown in Fig.23. The pull-off strength was $0.4 \mathrm{MPa}$ at a temperature of $28^{\circ} \mathrm{C}$. However, using a $0.4 \mathrm{MPa}$ bond strength between the base layer and the slab concrete in the numerical simulation resulted in total delamination between the slab concrete and the asphalt pavement. The asphalt pavement fell down as shown in Fig.22(b). The bond was lost due to the impact energy of the PC bar and the shear stress from self-weight of the asphalt pavement.

Therefore, in the numerical simulation it is necessary to use an appropriate interface material between the base layer and the slab concrete and between the base layer and the cover layer to obtain asphalt pavement deformation without total delamination (Fig.24). In the numerical simulation, the bond strength of the interface material between the base layer and the slab concrete was calibrated as 3.45 $\mathrm{MPa}$ and gave a result closer to the experiment as shown in Fig.22(c). This bond strength increment might be associated with the effect of strain rate as the bond delaminated at a high loading rate. 


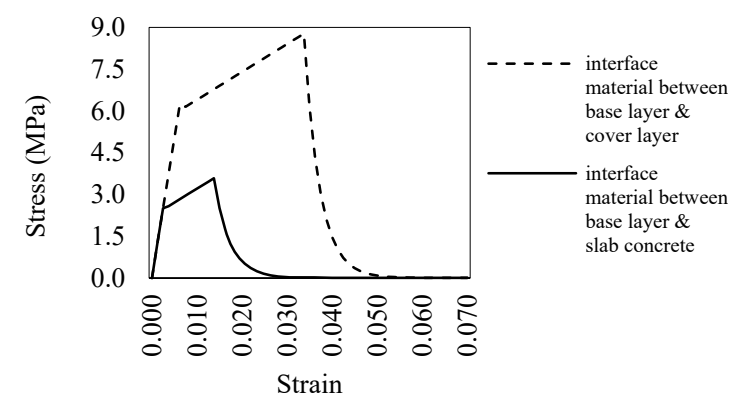

Fig.24 Interface bond materials.
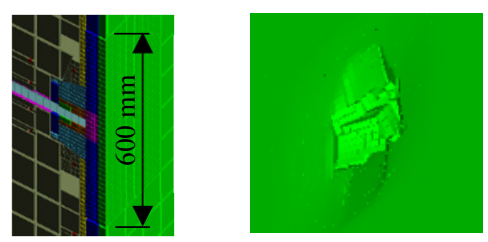

(a) Localized damage $(15 \mathrm{~mm} \times 14 \mathrm{~mm} \times 14 \mathrm{~mm}$ cover layer and $12.5 \mathrm{~mm} \times 14 \mathrm{~mm} \times 14 \mathrm{~mm}$ base layer element size over $600 \mathrm{~mm} \times 600 \mathrm{~mm}$ area)
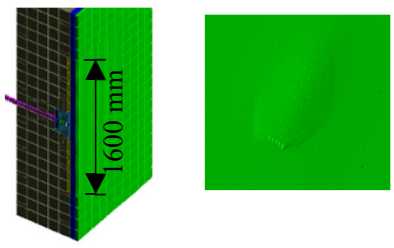

(b) Pavement deformation and small damage $(15 \mathrm{~mm} \times 14 \mathrm{~mm} \times 14$ $\mathrm{mm}$ cover layer and $12.5 \mathrm{~mm} \times 14$ $\mathrm{mm} \times 14 \mathrm{~mm}$ base layer element size over $1,600 \mathrm{~mm} \times 1,600 \mathrm{~mm}$ area and $30 \mathrm{~mm} \times 100 \mathrm{~mm} \times 100$ $\mathrm{mm}$ cover layer and $50 \mathrm{~mm} \times 100$ $\mathrm{mm} \times 100 \mathrm{~mm}$ base layer element size for other part)

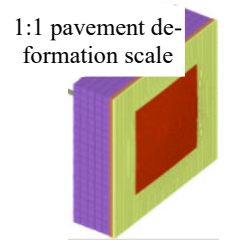

(c) Pavement deformation (15 $\mathrm{mm} \times 14 \mathrm{~mm} \times 14 \mathrm{~mm}$ cover layer and $12.5 \mathrm{~mm} \times 14 \mathrm{~mm} \times 14 \mathrm{~mm}$ base layer element size over $1,600 \mathrm{~mm} \times 1,600 \mathrm{~mm}$ area and $15 \mathrm{~mm} \times 20 \mathrm{~mm} \times 20 \mathrm{~mm}$ cover layer and $12.5 \mathrm{~mm} \times 20 \mathrm{~mm} \times 20$ $\mathrm{mm}$ base layer element size for other part)
Fig.25 Mesh division for appropriate simulation with less time.

In the numerical simulation, mesh sensitivity of the asphalt pavement was investigated to obtain appropriate asphalt pavement deformation and failure mode. A $12.5 \mathrm{~mm} \times 14 \mathrm{~mm} \times 14 \mathrm{~mm}$ element size for the base layer and a $15 \mathrm{~mm} \times 14 \mathrm{~mm} \times 14 \mathrm{~mm}$ element size for the cover layer were used over the area of 1,600 $\mathrm{mm} \times 1,600 \mathrm{~mm}$ as shown in red area in Fig. 25(c). The main reason for this meshing was that the asphalt pavement deformation was larger in the red area. For the rest of the asphalt pavement, a $12.5 \mathrm{~mm}$ $\times 20 \mathrm{~mm} \times 20 \mathrm{~mm}$ element size for the base layer and a $15 \mathrm{~mm} \times 20 \mathrm{~mm} \times 20 \mathrm{~mm}$ element size for the cover layer were used as shown in the yellow area in Fig. 23(c).

The normal contact stiffness factor $(N F)$, explained in section 4(1), of the asphalt pavement materials affects the interaction between the PC bar and the asphalt pavement and energy transfer between them. Providing a very high contact stiffness value c-

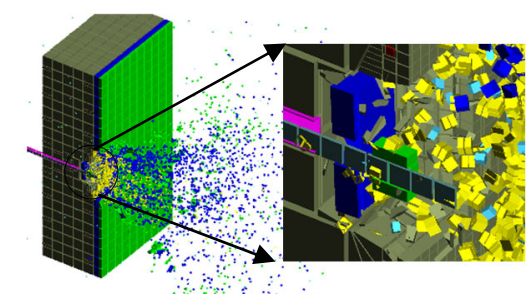

(a) $N F=0.25$

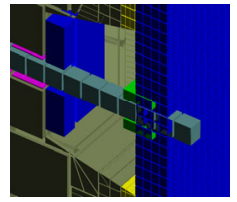

(b) $N F=0.0001$ (default value)

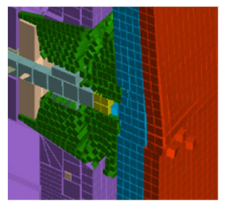

(c) $N F=0.05$
Fig.26 The effect of $N F$ on energy transfer between the PC bar and the asphalt pavement.

auses a large shock force transferred between elements, while providing a low contact stiffness value causes a reduction in the transmitted force when elements collide (Fig.26(a) and Fig.26(b)).

Therefore, the normal contact stiffness factor $(N F)$ should have a reasonable value. The numerical simulation with $N F$ value of 0.05 and shear contact stiffness factor $(S F)$ value of 0.001 for the base layer and the cover layer gave a result closer to the experiment as shown in Fig.26(c). On the other hand, for the mortar, $N F$ value of 0.1 and $S F$ value of 0.01 were used in the numerical simulation.

The mechanical properties of the hot mix asphalt (HMA) changed significantly under high-strain rate. The failure mechanisms under the high-strain rate loading were found to be considerably different from those obtained in static testing where failure of binder was a predominant mechanism ${ }^{50,51)}$. Highstrain rate loading caused trans-aggregate failures in addition to failure of the binder ${ }^{50}$. When the PC bar protruded, the asphalt pavement was fractured under a high loading rate. It was necessary to consider the effect of strain rate in the numerical simulation. For the asphalt pavement under high loading rate, the yield stress and the elastic modulus were increased by the respective $D I F$.

In this study, the empirical equations (equation (5) and (6)) to calculate the DIF of concrete were also applied for the asphalt pavements as literature on similar studies on asphalt materials is scarce. Highstrain rate mechanical behavior of bituminous materials has received little attention due to inherent difficulty in testing and interpretation of results ${ }^{50}$. The $D I F$ was calculated and considered in the numerical simulation by following the same procedure as in Section 5. The DIF was considered for the base layer and for the cover layer inside the red area of 1,600 $\mathrm{mm} \times 1,600 \mathrm{~mm}$ as shown in Fig.25(c). Material 
Table 3 The Dynamic Increase Factors.

\begin{tabular}{|c|c|c|}
\hline & \multicolumn{2}{|c|}{ Dynamic Increase Factor $(D I F)$} \\
\hline & Springs between & Springs between \\
\hline \multirow{2}{*}{$\begin{array}{c}\text { Material Proper- } \\
\text { ties } \\
\end{array}$} & the base layer ele- & the cover layer \\
\hline & ments & elements \\
\hline Yield stress & 2.39 & 6.00 \\
\hline Young modulus & 1.48 & 1.58 \\
\hline
\end{tabular}

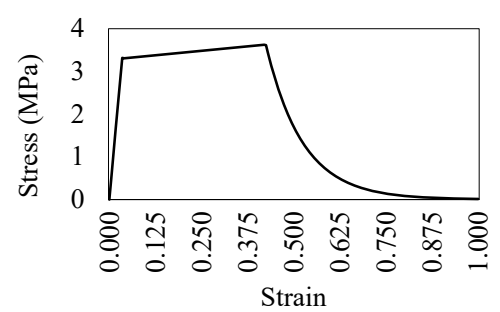

(a) Cover layer mateial

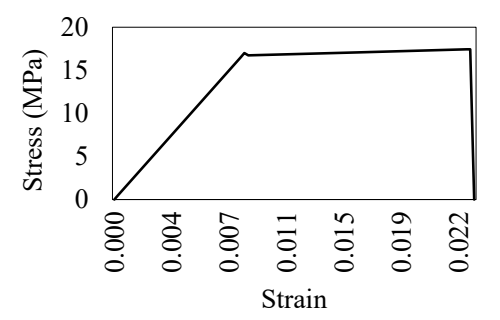

(b) Base layer material

Fig.27 Material properties of cover layer and base layer after considering strain rate.

properties of the cover layer and the base layer after considering strain rate effect are shown in Fig.27(a) and Fig. 27(b). The Dynamic Increase Factors $(D I F)$ that were calculated based on Equation (5) and (6) are shown in Table 3.

\section{(3) Result and discussion}

Immediately after the rupture of the PC bar, stress in the non-shrinking mortar was generated from the head of the nut and cracking was propagated diagonally with an angle of $35^{\circ}$ from the vertical axis. This stress distribution resulted in a cone-shaped crack in the mortar (Fig.28). As the PC bar tendon pushed the mortar forward, both the base layer and the cover layer asphalt pavement deformed together. At the same time, separation was observed at the interface between the slab concrete and the asphalt base layer as shown in Fig.29(b) and Fig.29(d). Separation was not observed between the two asphalt pavement layers. Small cracks were also observed on the surface of the cover layer asphalt pavement near the center of the PC bar as shown in Fig.29(a) and Fig.29(c).

The displacement of the PC bar in the numerical s-

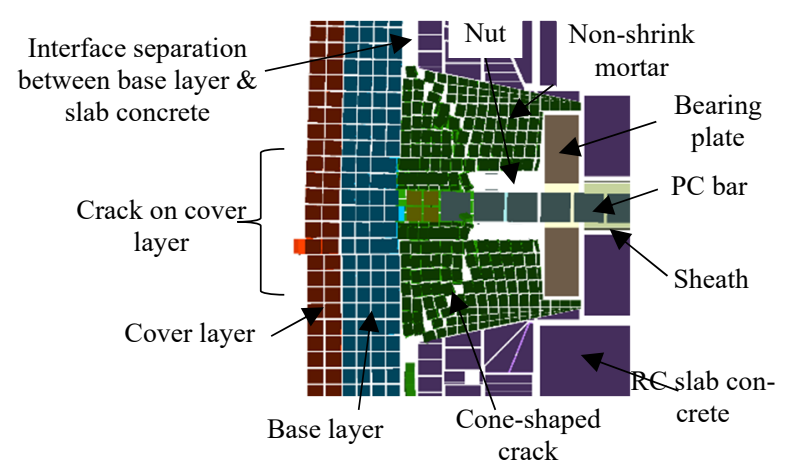

AEM numerical simulation
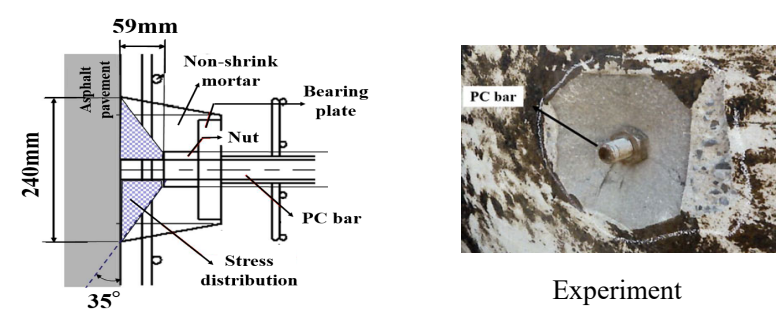

Fig.28 Failure mechanism after rupture of the PC bar.

imulation was observed in Fig.30(b). The maximum PC bar protrusion was $46 \mathrm{~mm}$ at 0.0169 second. After that, the PC bar moved in the reverse direction. Finally, the PC bar stopped moving at a protrusion of 9 $\mathrm{mm}$ after 0.18 second.

Deformation of the asphalt pavement was measured on the cover layer along the centerline of the connecting PC bars. In the numerical simulation, the asphalt pavement deformation was measured at 0.0169 second when maximum PC bar protrusion was observed, and at 0.10 second, 0.15 second, and 0.1828 second when PC bar protrusion was stopped (around $9 \mathrm{~mm}$ ) as shown in Fig.30(c). The asphalt pavement deformation at 0.1828 second is shown in Fig.30(a). The maximum asphalt pavement deformation was observed at 0.0169 second when the PC bar protrusion was maximum. After 0.0169 second, all strain energy of the PC bar $(4,408 \mathrm{~J})$ was dissipated by the asphalt pavement and the PC bar moved in the reverse direction. Similarly, after $0.0169 \mathrm{sec}-$ ond the asphalt pavement deformed in the reverse direction. Both the experiment and the numerical simulation showed that the maximum cover layer deformation was observed at the center of the section and deformation was decreasing towards the edges in the section. The experiment showed $23 \mathrm{~mm}$ residual deformation at the center of cover layer and $3 \mathrm{~mm}$ deformation at $600 \mathrm{~mm}$ from the center on both sides. In the numerical simulation, at 0.1 second, $0.15 \mathrm{sec}-$ ond, and 0.1828 second, the maximum cover layer deformation was around $16 \mathrm{~mm}$ at the center of the section and gradually decreased towards the edge of the cover layer. 


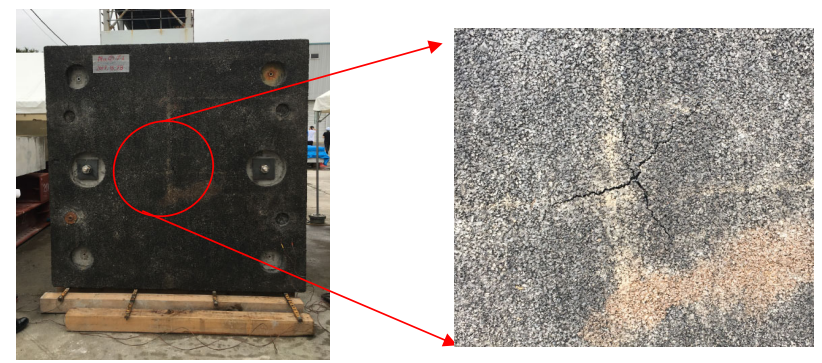

(a) Crack on the cover asphalt layer

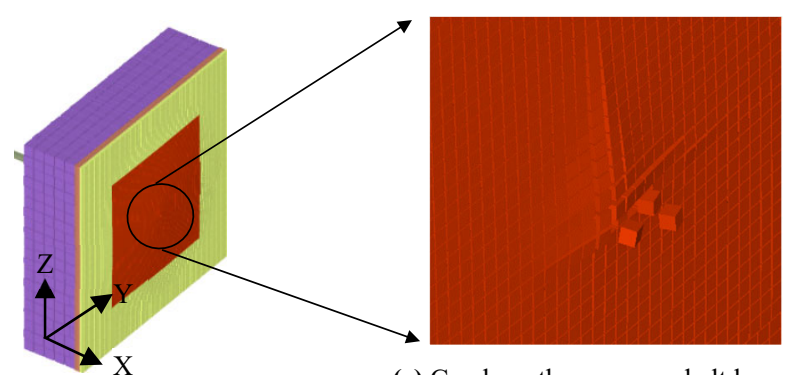

(c) Crack on the cover asphalt layer

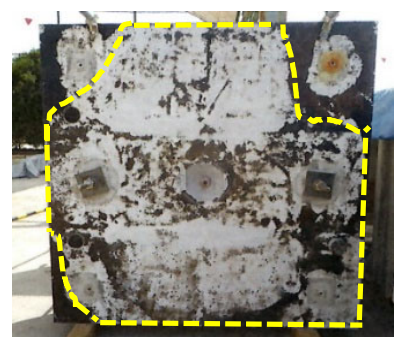

(b) The area inside yellow line showed the observed interface crack between slab concrete and asphalt pavement

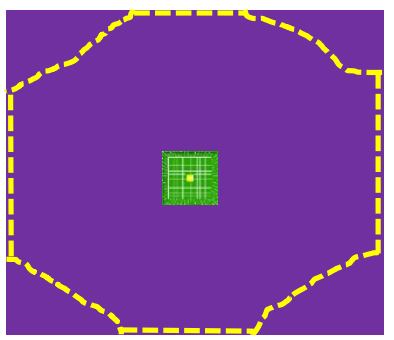

(d) The area inside yellow line showed the observed interface crack between slab concrete and asphalt pavement

Fig.29 Asphalt pavement crack \& interface separation, experiment (a \& b) and numerical simulation at 0.1828 second (c \& d).

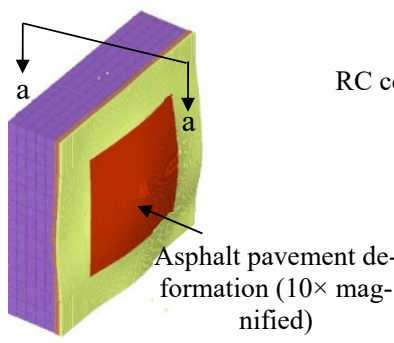

(a) pavement deformation at 0.1828 second

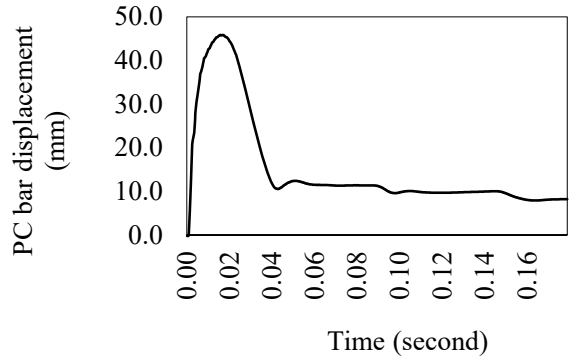

(b) Protrusion of PC bar (measured on the PC bar head before and after PC bar rupture)

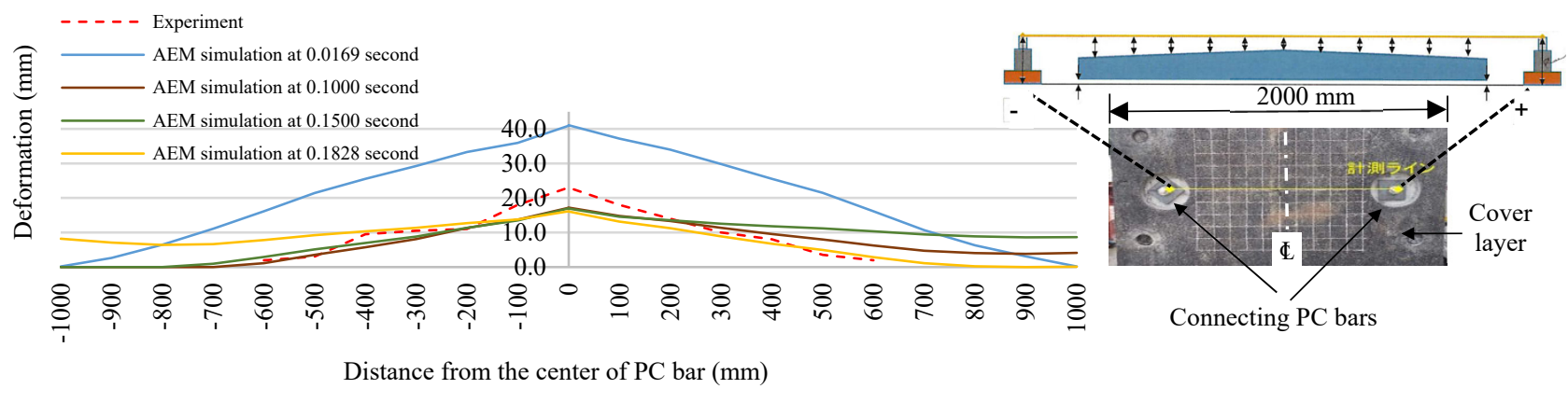

(c) Asphalt pavement deformation

Fig.30 Asphalt pavement deformation and protrusion of the PC bar.

The cover layer deformation was asymmetry in the experiment and in the numerical simulation. In the numerical simulation, at 0.1 second, the cover layer deformation was $4 \mathrm{~mm}$ at $1,000 \mathrm{~mm}$ from the center of cover layer, but the deformation was $0 \mathrm{~mm}$ at $1,000 \mathrm{~mm}$. On the other hand, at 0.1828 second, the cover layer deformation was $0 \mathrm{~mm}$ at $1,000 \mathrm{~mm}$ from the center of cover layer, but the deformation was 8 $\mathrm{mm}$ at $-1,000 \mathrm{~mm}$. Both at 0.1 second and at 0.1828 second, the PC bar protrusion (Fig. 30(b)) was around $9 \mathrm{~mm}$ and the interface bond delamination between the base layer and the slab concrete (Fig.29(d)) was the same. The difference in cover layer deformation at 0.1 second and at 0.1828 second was due to the shock wave (which originated at the center of the cover layer when the PC bar impacted the asphlt pavement) and due to its reflection at the free boundary. As a result, the cover layer was deformed inward 
and outward around the edge at different times. However, this deformation must be decreasing with time according to the dissipation of strain energy.

From this investigation, the asphalt pavement system was proven effective in preventing PC bar protrusion and concrete spalling. The effectiveness of the asphalt pavement system depends on so many factors, such as energy of ruptured PC bars, material properties of asphalt pavements including time-dependent deterioration, temperature, etc. The numerical simulation tool developed in this study will be utilized for detailed investigation of the protrusion behavior and for evaluating the effectiveness of countermeasures.

\section{CONCLUSION}

Based on experimental and numerical simulation using the Applied Element Method to study the rupture and protrusion of vertically tightened PC bars in PC girders with asphalt pavement, the following conclusions were obtained:

1. Appropriate numerical simulation with the AEM can be conducted with appropriate interface material property between the slab concrete and the asphalt pavement layers, considering the fracture energy of concrete, with appropriate mesh discretization, appropriate time interval, appropriate Normal Contact Stiffness Factor $(N F)$, and considering strain rate effects both in concrete and in asphalt pavement.

2. Cover concrete of $15 \mathrm{~mm}$ alone could not prevent the protrusion of a PC bar of $4.5 \mathrm{~m}$ rupture length.

3. The asphalt pavement system with appropriate material and thickness could prevent the protrusion of the PC bar of $4.5 \mathrm{~m}$ rupture length and concrete spalling. The experimental results proved that the asphalt pavement system used in this study, without using a steel plate and FRP sheet, was effective against 4,408 J impact energy. The effectiveness of the pavement system was also confirmed in the numerical simulation.

4. In the asphalt pavement system, the PC bar protrusion was prevented by ductile deformation of asphalt pavement delaminated from slab concrete. The strain energy of the PC bar was dissipated by a simultaneous action of asphalt pavement deformation, coneshaped crack in the mortar, and interface delamination between the slab concrete and the asphalt pavement.

\section{REFERENCES}

1) Transportation Research Board : Methods of Strengthening Existing Highway Bridges, National Cooperative Highway Research Program Report 293, pp. 68-69, 1987.

2) OECD : Organization for Economic Co-Operation and Development Scientific Expert Group, Bridge Rehabilitation and Strengthening, Paris, p. 103, 1983.

3) Corven, J. and Moreton, A. : Post-Tensioning Tendon Installation and Grouting Manual, U.S. Department of Transportation Federal Highway Administration (FHWA), FHWA-NHI-13-026, Version 2, pp. 5-1, 2013.

4) Minh, H., Mutsuyoshi, H., Taniguchi, H. and Niitani, K. : Study on chloride-induced corrosion in post-tensioned concrete beams with insufficient grout condition, Annual Journal of Concrete Engineering, Vol. 27, No. 1, pp. 967-972, 2005.

5) ACI: Corrosion of Prestressing Steels, Reported by $A C I$ Committee 222, ACI 222.2R, pp. 01-38, 2001.

6) Podolny, W. : Corrosion of prestressing steels and its mitigation, Journal of the Prestressed Concrete Institute, Vol. 27, Issue 5, pp. 34-55, 1992.

7) Freyermuth, C. L. : Status of the durability of post- tensioning tendons in the United States, Durability of Post- tensioning tendons, fib-IABSE Technical Report, Bulletin 15. Workshop 15-16 November 2001, Ghent (Belgium), pp. 4350,2001

8) Godart, B. : Status of durability of post tension tendons in France, Durability of Post-tensioning tendons, fib-IABSE Technical Report, Bulletin 15. Workshop 15-16 November 2001, Ghent (Belgium), pp. 25-42, 2001.

9) Aoki, K., Umitsu, M. and Igo, Y. : Strategies for improvement-approach in Japan, Durability of Post-tensioning tendons, fib-IABSE Technical Report, Bulletin 15. Workshop 15-16 November 2001, Ghent (Belgium), pp. 263-277, 2001.

10) Jungwirth, D. : Problems, Solutions and Developments for Post-Tensioning Tendons from the German Point of View, Durability of Post-tensioning tendons, fib-IABSE Technical Report, Bulletin 15. Workshop 15-16 November 2001, Ghent (Belgium), pp. 11-24, 2001.

11) Wicke, M. : Repair and strengthening of damaged tendons and structures, Durability of Post-tensioning tendons, fibIABSE Technical Report, Bulletin 15. Workshop 15-16 November 2001, Ghent (Belgium), pp. 109-120, 2001.

12) Fuzier, J. P. : Development of grout and grouting techniques, Durability of Post-tensioning tendons, fib-IABSE Technical Report, Bulletin 15. Workshop 15-16 November 2001, Ghent (Belgium), pp. 173-194, 2001.

13) Mutsuyoshi, H. : Present situation of durability of post-tensioned PC bridges in Japan, Durability of Post-tensioning tendons, fib-IABSE Technical Report, Bulletin 15. Workshop 15-16 November 2001, Ghent (Belgium), pp. 75-88, 2001.

14) Woodward, R. : Durability of post-tensioned tendons on road bridges in the UK, Durability of Post-tensioning tendons, fib-IABSE Technical Report, Bulletin 15. Workshop 15-16 November 2001, Ghent (Belgium), pp. 1-10, 2001.

15) Fallis, G., Ball, J. C. and Moad, A. : Innovative corrosion evaluation system for unbonded post-tensioned cables, Concrete Repair Bulletin, pp. 7-8, 2007.

16) Isuru, W., Hiroshi, M. and Toshihiro, Y. : Effects of tendon rupture and re-grouting on the flexural behavior of prestressed concrete beams, 10th International Conference on Short and Medium Span Bridges Quebec City, Quebec, Canada, 154, pp. 1-10, 2018.

17) Abdelatif, A. O., Owen J. S. and Hussein, M. F. M. : Reanchorage of a ruptured tendon in bonded post-tensioned 
concrete beams: model validation, Key Engineering Materials, DOI: 10.4028/www.scientific.net/KEM.569- 570.302, pp. 302-309, 2013.

18) Nishi, H., Otsuka, T., Kamei, K. and Onishi, H. : Risk assessment about the maintenance of the PC bridge in Tozai Line, Journal of the Society of Material Science, Japan, Vol. 67, No. 2, pp. 163-169, 2018.

19) Harder, J. and Webster, N. R. : Durability of post-tensioning tendons: Canadian experience, Durability of Post- tensioning tendons, fib-IABSE Technical Report, Bulletin 15. Workshop 15-16 November 2001, Ghent (Belgium), pp. 5173, 2001

20) Schupack, M. and Suarez, M. G. : Some recent corrosion embrittlement failures of prestressing systems in the United States, Journal of the Prestressed Concrete Institute, Vol. 27, No. 2, pp. 38-55, 1982.

21) Kamada, T. : The latest non-destructive inspection technologies for evaluation of grouting condition of tendon ducts in prestressed concrete beams, Third International Conference on Sustainable Construction Materials and Technologies, ISSN 2515-3056, 2013.

22) Täljsten, B., Paulsson, B. and Elfgren, L.: Prestressed concrete bridges condition assessment and future challenges, Luleå University of Technology, Department of Civil, Environmental and Natural Resources Engineering, BBT 2017011, Trafikverket, TRV 2018/28332, ID 6686, pp. 13-20, 2019.

23) Moore, D. G., Klodt, D. T. and Hensen, R. J. : Protection of steel in prestressed concrete bridges, National Cooperative Highway Research Program Report 90, University of Denver, Colorado, pp. 5-20, 1970.

24) Nagata, Y., Shiratori, A., Ito, T. and Ueki, H. : Diagnosis for grouted condition of transverse prestressing tendon in PC bridges in-service using impact elastic wave methods, Concrete Research and Technology, Vol. 25, pp. 57-64, 2014.

25) Naso, T. R. : A stitch in time saves nine: A post tensioning repair case study, Journal of Post Tensioning Institute, Vol. 13, No. 2, pp. 53-60, 2017.

26) Bonger, A., Hosoda, A., Hamed, S. and Kaba, K. : Numerical simulation of rupture protrusion of vertically tightened PC steel bars using Applied Element Method, Internet Journal of Society for Social Management Systems, Vol. 12, Issue 1, SMS19-3671, ISSN: 2432-552X, pp. 110, 2019a.

27) Bonger, A., Fukuhara, S., Hosoda, A., Hamed, S., Fukaya, $\mathrm{T}$. and Kaba, K. : Rupture and protrusion of vertically tightened PC bars of PC bridges, 11th International Conference of the IFHS on Extreme Engineering, ISBN: 978-981-141937-9, pp. 161-170, 2019b.

28) Hamada, Y., Ishikawa, Y., Mizoe, M. and Miyagawa, T.: Maintenance of prestressed concrete bridges, Durability of Post-tensioning tendons, fib-IABSE Technical Report, Bulletin 15. Workshop 15-16 November 2001, Ghent (Belgium), pp. 109-120, 2001.

29) Tagel-Din, H. and Meguro, K. : Applied element simulation for collapse analysis of structures, Bulletin of Earthquake Resistance Structures, No. 32, pp. 113-123, 1999.

30) Tagel-Din, H. and Meguro, K. : Applied Element Method for dynamic large deformation analysis of structures, Structural Eng. / Earthquake Eng., JSCE, Vol. 17, No. 2, pp. 215224, 2000.

31) Tagel-Din, H. and Meguro, K. : Applied Element Method for structural analysis, theory and application for linear materials, Journal of Doboku Gakkai Ronbunshu, No. 647, pp. $31-45,2000$.

32) Tagel-Din, H. and Meguro, K. : Nonlinear simulation of RC structures using Applied Element Method, Journal of Doboku Gakkai Ronbunshu, Vol. 17, No. 654, pp. 13-24,
2000.

33) Meguro, K. and Tagel-Din, H. : Applied Element Method used for large displacement structural analysis, Journal of Natural Disaster Science, Vol. 24, No. 1, pp. 25-34, 2002.

34) Applied Science International, Available at: $<$ http://www. Extreme Loading for Structures (ELS)>, 2017.

35) Helmy, H., Salem, H. and Mourad, S. : Progressive collapse assessment of framed reinforced concrete structures according to UFC guidelines for alternative path method, Engineering Structures, Vol. 42, pp. 127-141, 2012.

36) Salem, H., Mohssen, S., Kosa, K. and Hosoda, A. : Collapse analysis of Utatsu Ohashi bridge damaged by Tohoku tsunami using Applied Element Method, Journal of Advanced Concrete Technology, Vol. 12, pp. 388-402, 2014.

37) Salem, H. and Helmy, H. : Numerical investigation of collapse of the Minnesota I-35W bridge, Engineering Structures, Vol. 59, pp. 635-645, 2014.

38) Elshaer, A., Mostafa, H. and Salem, H. : Progressive collapse assessment of multistory reinforced concrete structures subjected to seismic actions, KSCE Journal of Civil Engineering, Vol. 21, pp. 184-194, 2016.

39) Garofano, A. and Lestuzzi, P. : Seismic assessment of a historical masonry building in Switzerland: The "Ancien Hôpital De Sion", International Journal of Architectural Heritage, Vol. 10, pp. 975-992, 2016.

40) Cismasiu, C., Ramos, A. P., Moldovan, I. D., Ferreira, D. F. and Filho, J. B. : Applied element method simulation of experimental failure modes in RC shear walls, Computers and Concrete, Vol. 19 (4), pp. 365-374, 2017.

41) Zerin, A., Hosoda, A., Salem, H. and Amanat, K. : Seismic performance evaluation of masonry infilled reinforced concrete buildings utilizing verified masonry properties in Applied Element Method, Journal of Advanced Concrete Technology, Vol. 15, pp. 227-243, 2017.

42) Grunwald, C., Khalil, H., Schaufelberger, B. and Ricciardi, E. : Reliability of collapse simulation - Comparing finite and Applied Element Method at different levels, Engineering Structures, Vol. 176, pp. 265-278, 2018.

43) Maekawa, K. and Okamura, H.,: The deformational behavior and constitutive equation of concrete using the elastoplastic and fracture model, Journal of the Faculty of Engineering, The University of Tokyo (B), Vol. 37 (2), pp. 253$328,1983$.

44) JSCE, Standard Specifications for Concrete Structures (Design), Guideline for concrete, Tokyo: JSCE, ISBN 978-48106-0777-2, pp. 42, 2017.

45) Maekawa, K., Pimanmas, A. and Okamura, H. : Non-Linear Mechanics of Reinforced Concrete, CRC Press, pp. 29-31, 2003.

46) Bischoff, P. H. and Perry, S. H. : Compressive behavior of concrete at high strain rates, Materials and Structures Materiaux et Constructions, Vol. 24, pp. 425-450, 1991.

47) Pająk, M. : The influence of the strain rate on the strength of concrete taking into account the experimental techniques, Silesian University of Technology, No. 3, pp. 77-86, 2011.

48) Riisgaard, B., Ngo, T., Mendis, P., Georgakis, C. and Stang, $\mathrm{H}$. : Dynamic increase factors for high performance concrete in compression using split Hopkinson pressure bar, 6th International Conference on Fracture Mechanics of Concrete and Concrete Structures, Vol. 1-3, 2007.

49) Obi, H., Kanoh, K., Nanai, S. and Sueda, T. : Comparative analysis of concrete and UFC construction subject to impact load, Concrete Engineering Annual Papers, Vol. 28, No. 2, pp. 841-846, 2006.

50) Tekalur, S. A., Shukla, A., Sadd, M. and Lee, K. W. : Mechanical characterization of a bituminous mix under quasistatic and highstrain rate loading, Construction and Building 
Materials, Vol. 23, pp. 1795-1802, 2009.

51) Tang, R., Yu, Z., Liu, G., Li, F. and Tang, W. : Uniaxial dynamic compressive behaviors of hydraulic asphalt concrete under the coupling effect between temperature and strain rate, MDPI Journal, Materials, Vol. 13, 5348; doi:10. 3390/ma13235348, 2020.

(Received June 14, 2021)

(Accepted December 20, 2021) 